\title{
APLICACIÓN DE UN MODELO PARA EL ORDENAMIENTO AMBIENTAL DE UN ESPACIO RURAL SUJETO A LA PRESIÓN DEL CRECIMIENTO URBANO. ESTUDIO DE CASO
}

\author{
Mg. Prof. Jorge Alfredo ALBERTO \\ Instituto de Geografía. Facultad de Humanidades \\ UNNE
}

\begin{abstract}
RESUMEN: Para el desarrollo del presente trabajo se ha seleccionado un área del ámbito periurbano del Gran Resistencia localizada a unos $10 \mathrm{~km}$. al norte del mismo.

Dicha área en los últimos años ha presentado fuertes cambios en relación al uso del suelo, donde el elevado parcelamiento y la existencia de diferentes infraestructuras estarían indicando una fuerte presión de la ocupación con todas la problemáticas ambientales derivadas de ello.

Teniendo en cuenta esta problemática se trabaja una metodología para el estudio del paisaje integrado, apoyada en una concepción del paisaje geográfica y sistémica.

El modelo utilizado responde a la necesidad de analizar y caracterizar el proceso de urbanización incipiente; valiéndose para ello de bases cartográficas de síntesis e históricas, fotografías aéreas, imágenes satelitales orientadas al uso de herramientas informáticas.
\end{abstract}

Palabras clave: Ordenamiento ambiental, ambientes periurbanos, crecimiento urbano, escenarios futuros.

\section{APPLICATION OF A MODEL FOR OF ENVIRONMENTAL CLASSIFICATION OF A RURAL SPACE SUBJECT TO THE PRESSURE OF THE URBAN GROWTH. I STUDY OF CASE}

ABSTRACT: In order to develop the present study, we selected a periurban area located $10 \mathrm{~km}$ towards north of the Gran Resistencia city.

This area supported important changes in land use during the last years. The extreme proccesses of land dividing into plots as well as the infrastructural different frameworks indicates a strong pressure derived from human occupation. This procces originated several problems related with this situation.

Over this natural and human problematic scenary, we overcome the study using a methodology that applied the integrated landscape geographical study. The methodology is supported as well in the sistemic and geographical landscape conception.

The model used embraces too the necessity of analyze the incipient urban proccesses. In this order, we employed basical synthesis chartographic maps as well historic ones. Also, we employed aerial photographies and satellitary images addressed to the use of informatic tools concerning with these problems.

Key word: environment management, periurban environment, urban growth, future scenaries. 


\section{INTRODUCCIÓN:}

En los últimos tiempos la preocupación por las cuestiones ambientales ha crecido considerablemente en todo el mundo; así los aspectos ecológicos se transformaron en temas de máxima importancia en todas las actividades humanas, principalmente los vinculados a los grandes centros urbanos.

Dentro de este contexto una preocupación especial continúa siendo el desarrollo de los sistemas periurbanos, los que crecen sobre el ámbito rural por la expansión de las márgenes de las ciudades en forma de "anillos" o por la extensión a través de "corredores", espacios donde existen una compleja interface de construcciones edilicias con ambientes naturales y agropecuarios.

Uno de los problemas ambientales del Gran Resistencia es la diversidad de usos del suelo y la velocidad con el mismo se da aumentando sus incidencias. Cada uso genera un impacto negativo, o proceso degradante particular, en el paisaje y en sus recursos (agua, suelo, aire, bosque, etc.) por la mala planificación del manejo de éstos.

\section{OBJETIVOS:}

Como objetivo general de este trabajo, se intentará plantear un modelo que permita analizar el proceso de ocupación en un área rural específica (en este caso un área periurbana ubicada al norte del AMGR.) y proyectar escenarios de futuro para desarrollar, en lo posible, escenarios de gestión.

\section{Objetivos específicos}

- Establecer las variables que influyen en el proceso de ocupación de un ambiente rural bajo la presión de un ámbito urbano.

- Proponer un método que permita estudiar y estimar el comportamiento del proceso de ocupación de un ambiente rural bajo la presión del crecimiento urbano.

- Determinar los aspectos positivos y negativos en la sociedad resultantes del proceso espontaneo de ocupación del sistema natural del área en cuestión.

- Establecer las condiciones deseables de ocupación del espacio desde el punto de vista ambiental en el área delimitada para su estudio.

- Plantear escenarios de futuro sobre el ordenamiento de un espacio rural acorde al proceso de urbanización incipiente.

\section{MATERIALES, MÉTODOS Y TÉCNICAS:}

Se trabaja una metodología para el estudio integrado del paisaje, apoyada en una concepción geográfica y sistémica del paisaje. El método utilizado responde a la necesidad de analizar y caracterizar el proceso de urbanización incipiente; valiéndose para ello de bases cartográficas de síntesis e históricas, fotografías aéreas (1962 y 1977), imágenes satelitales (LandSAT TM 1997 y 1998). Estos recursos metodológicos están orientados al uso de herramientas informáticas (CAD para diseño asistido y SIG para el análisis) que permitan analizar y evaluar las diferentes variables ambientales.

La aplicación de la metodología debió considerar la problemática derivada de las múltiples acepciones y usos del término "paisaje" y de los variados enfoques, métodos y contenidos que pueden llegar a tener estudios que conlleven dicho concepto. 
Para el desarrollo de este modelo teórico - cartográfico, en primer lugar, se establecieron las variables que influyeron en el proceso de ocupación urbano sobre el rural, para ello:

- Se proyectó un modelo de tipo cualitativo que permitió identificar fortalezas, oportunidades, debilidades y amenazas que posee el área rural estudiada bajo la presión del crecimiento urbano.

- Se aplicó el mismo, al área de estudio, en diferentes cortes temporales referidos al proceso de ocupación para los años 1960, 1970, 1980, y 1990.

- A partir de su aplicación y del análisis de la evolución de la ocupación se identifico las variables más significativas que controlan dicho proceso.

A continuación, se analizaron los aspectos positivos y negativos desde el punto de vista social del proceso espontáneo de ocupación del sistema natural y antrópico del área en cuestión; situación que posibilitó determinar las principales problemáticas ambientales.

Teniendo en cuenta la situación resultante del análisis anterior, se determinaron condiciones tendenciales de ocupación del espacio en el área de estudio.

Finalmente, conocidas las principales variables que controlan el proceso de ocupación, se plantearon pautas de gestión que propendan a lograr las condiciones deseables de ocupación del espacio para el área de estudio.

Para ello, el modelo propuesto, fue organizado en cinco fases:

Fase I. Ubicación: Se realizó la selección y delimitación del área rural sujeta al ordenamiento ambiental, teniendo en cuenta para ello su sitio y situación con respecto a un gran centro urbano con funciones marcadas que organizan la región, como es el caso del AMGR.

Fase II. Caracterización: Se llevó adelante una descripción y análisis de las características del medio físico, biótico y socioeconómico, a partir del cruzamiento de información cartográfica generada y documental existente, apoyada en gran parte por trabajos de campo y relevamiento fotográfico.

Fase III. Prediagnóstico: Se confeccionó una delimitación de Unidades Ambientales a partir de descripción, inventario y análisis. Los mismos se realizan Fig. 1: MODELO PROPUESTO

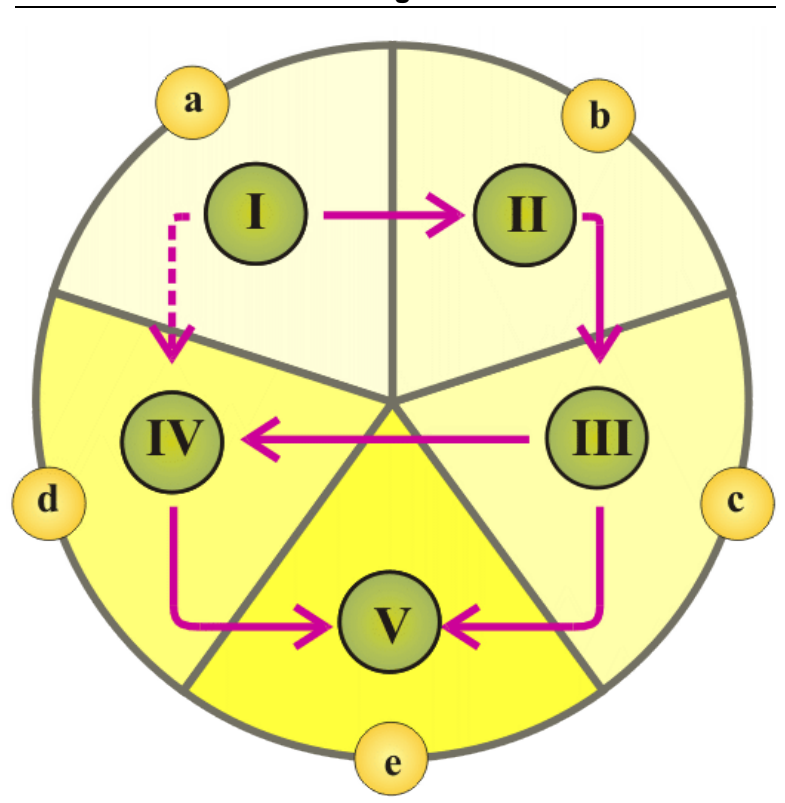
por medio de la aplicación de Matrices DAFO (debilidades - amenazas fortalezas - oportunidades); complementadas y apoyadas con Matrices de Correlación de Fenómenos Naturales y Antrópicos, teniendo en cuenta sus implicancias, tendencias y varianzas sobre las áreas delimitadas y sus alrededores. 
- Fase IV. Diagnóstico: Se realizó un análisis más detallado y ya centrado sobre los problemas identificados en la etapa anterior, y a partir de ello se definieron objetivos. La definición de los mismos consiste en la expresión formal de resolver los problemas planteados, aprovechar las oportunidades, satisfacer las aspiraciones y prevenir las disfunciones futuras que la evolución del sistema permite detectar. Para analizar los problemas se procedió a la confección de árboles que reflejan los problemas detectados, destacando las causas que los generan y las consecuencias derivadas y, además el planteo de los objetivos para superarlos, es decir las líneas de acción y los efectos esperados.

- Fase V. Pautas de Gestión: Se propusieron las condiciones necesarias para el desarrollo del área en cuestión, organizadas en escenarios futuros que se fueron esquematizando de manera cartográfica. Esta última fase consta de tres partes: la definición de objetivos, el planteo de alternativas y el bosquejo de escenarios futuros (tendenciales y deseados) a partir de la correlación de las dos primeras partes.

Cabe destacar que para el estudio y análisis de la multiplicidad de variables que intervienen en el comportamiento y la evolución proceso de ocupación se emplearon en gran parte del trabajo herramientas como la fotointerpretación, el procesamiento digital de imágenes y los sistemas de información geográfica, ya detallados.

\section{APLICACIÓN DEL MODELO PROPUESTO}

\section{Fase I. UBICACIÓN:}

Para la realización del presente trabajo se ha escogido como área de estudio una superficie aproximada a $100 \mathrm{~km}^{2}$ (10 km de ancho, con sentido NE a SO por $10 \mathrm{~km}$ de largo, con sentido NO a SE) localizada en el sector oriental de la Provincia del Chaco, cruzada por el paralelo de $27^{\circ} 19^{\prime}$ latitud Sur y el meridiano de $58^{\circ} 59^{\prime}$ longitud Oeste.

La misma responde a un área del ámbito periurbano del Gran Resistencia, localizada a unos $10 \mathrm{~km}$. al norte del mismo, atravesada por el río Tragadero y la ruta Nacional $\mathrm{n}^{\circ}$ 11, en la cual se encuentran poblados como Colonia Benitez y Tres Horquetas, y parajes como Campo Rossi y El Tropezón. 
Comprende parte de los Departamentos Libertad (Circunscripción II Sección A), San Fernando (Circunscripción II Sección A) y $1^{\circ}$ de Mayo (Circunscripción VIII, IX, X) según el catastro de la Provincia del Chaco.

Fig. 2: UBICACIÓN DEL AREA DE ESTUDIO

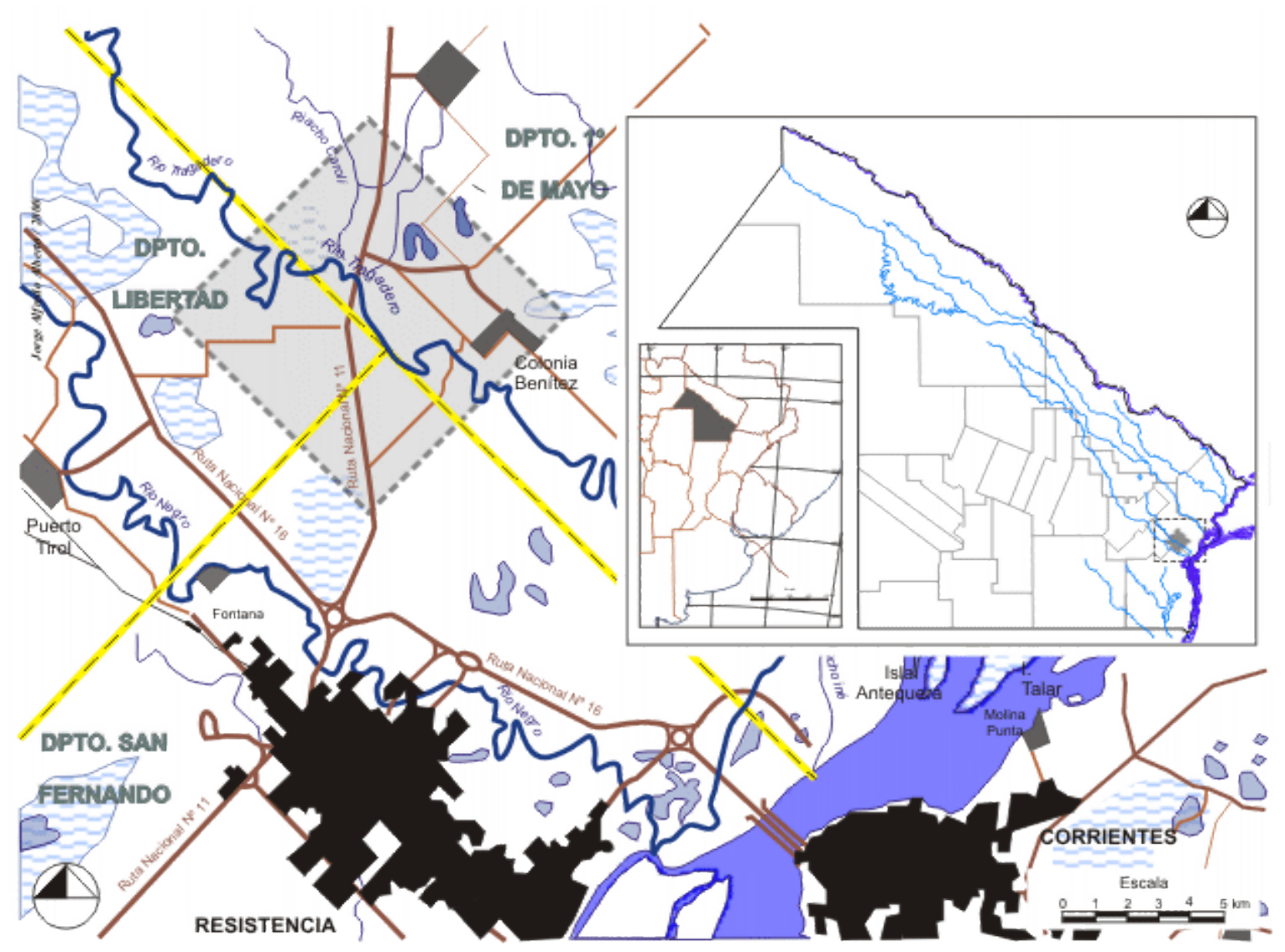

Fase II. CARACTERIZACIÓN

\section{a. Condiciones naturales:}

En detalle, el área de estudio es una planicie de acumulación que sustenta paleomodelos fluviales periódicamente inundables. Comprende específicamente parte de la cuenca del río Tragadero asentada sobre paleoderrames, cuyos rasgos dominantes son los continuos y progresivos procesos generalizados de erosión - sedimentación complementados con la colmatación de biomasa muerta. Todo estas condiciones dan lugar a una heterogeneidad interna que permiten determinar una diferenciación de zonas subordinadas entre sí; según se detalla: 
a) Zona de Paleoderrames: Son el resultado de la existencia de enormes paleoconoides aluviales del Bermejo que se superpusieron al modelado estructural originando numerosos brazos divergentes, con derrames laterales que sobreelevaron de la planicie, sustentando, en la actualidad, formaciones boscosas y dejado entre ellos planicies embutidas.

b) Zona de Planicie Fluvial (o de Divagación): Es el valle o área de ambientes anegadizos retrabajados por el río Tragadero y sus afluentes dentro de los paleoderrames. En los mismos se observan la presencia de áreas boscosas atomizadas, con predominio de leñosas en las áreas más elevadas, que degradan periféricamente en abras, pudiendo estar asociadas a

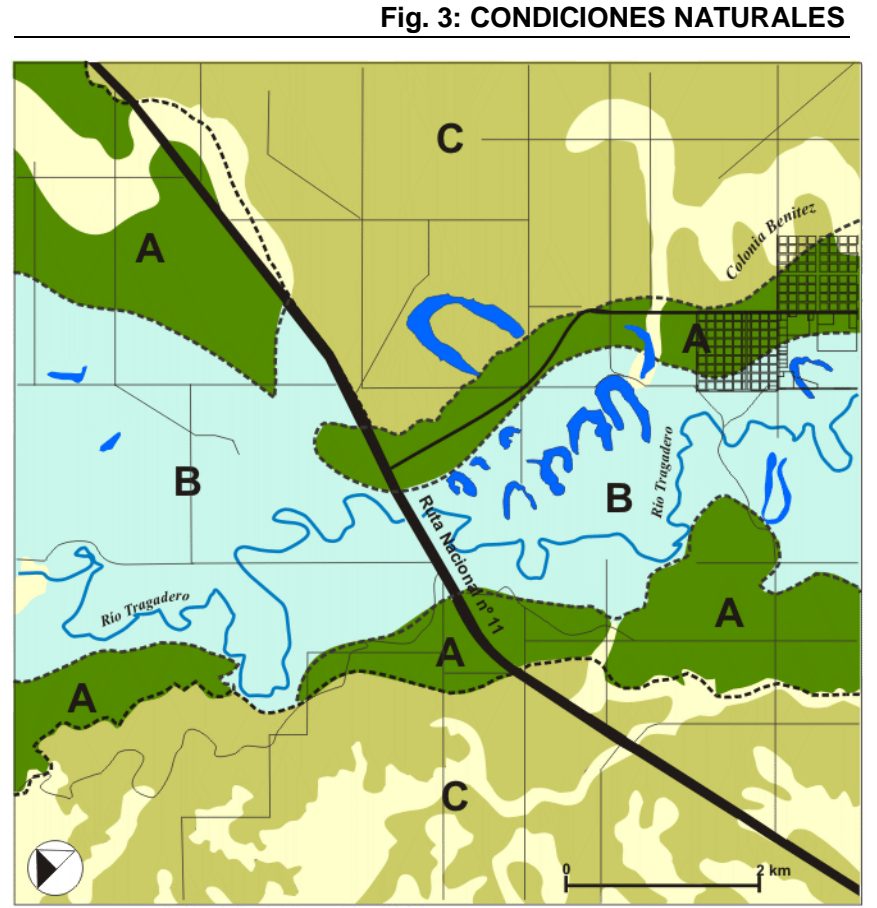

CONDICIONES GEOMORFOLÓGICAS

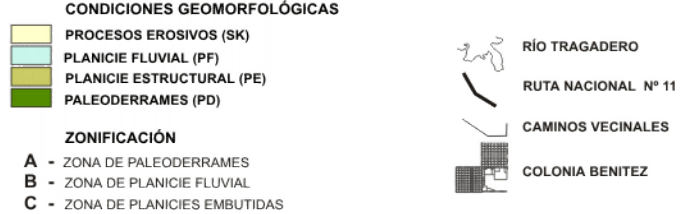
formaciones mixtas.

Sobre los albardones elaborados por el río Tragadero o los riachos Quintana y Carolí crecen formaciones boscosas denominada bosque en galería o de ribera que guarda cierta analogía con los denominados monte alto. Posee características heterogéneas conformada por árboles de gran porte (20 a 30 metros de altura) debajo de los cuales crecen arbustos, lianas, helechos, cardos, orquídeas, etc., presentando suelos arenosos, aireados y bien drenados.

c) Zona de Planicies Embutidas: La misma se caracteriza por tener terrenos encerrados por de los diferentes regueros o paleoderrames. Dichos terrenos se comportan como cubetas donde el escurrimiento hídrico es lento y de permanencia temporal debido a la escasa pendiente.

Estas condiciones determinan la presencia de ambientes permanentes o periódicamente anegadizos donde predominan gramíneas duras, de los géneros Elionorus, Andropogón, Panicum, Paspalum y otras plantas herbáceas, especialmente Compuestas y Leguminosas. Entre estos se intercalan ambientes de menor extensión no inundables, ocupados por coberturas leñosas que se encuentran agrupadas en formaciones boscosas cerradas con abras de pajonales $u$ otras higrófilas, que pueden estar asociadas a paleoformas fluviales y eólicas.

\section{b. Proceso de ocupación del espacio}

El área de estudio esta sujeta a la influencia de antiguas colonias agrícolas forestales como Colonia Benitez y Margarita Belén, distantes a 17 y $21 \mathrm{~km}$. de 
Resistencia respectivamente y aproximadamente $7 \mathrm{~km}$. entre sí. Las mismas han surgido a fines del siglo XIX, a partir de la concesión de tierras a empresas para la fundación de colonias agrícolas y la explotación de los bosques de quebracho colorado, y con el tiempo, cultivos de algodón complementados con plantaciones de caña de azúcar. Esto trajo aparejado la presencia de fábricas dedicadas a la obtención de tanino, desmotado de la fibra de algodón y elaboración de melaza, azúcar y alcohol, que respondían a capitales privados locales o extranjeros.

La lenta desaparición de las fábricas estuvo sujeta a la poca rentabilidad económica de la explotación de los recursos naturales que brindaban la materia prima, en gran parte por el empobrecimiento del número de ejemplares de importancia tánica en los bosques de quebracho colorado, el agotamiento de los suelos y, un bajo precio en el mercado de los productos derivados. Todo estos factores condicionaron la crisis de estas colonias, con el consecuente estancamiento de su crecimiento y posterior proceso migratorio de su población hacia Resistencia.

A pesar de esta situación, en la década del 60 los cultivos de plantación como el algodón y tabaco se desarrollaron sobre la planicie embutida, en extensiones superiores a las 50 has. por productor. Estos cultivos respondían a planteos económicos para mercados extraregionales, los cuales se sustentaban en de políticas de potenciación por parte del gobierno y a las cotizaciones imperantes por esos años en el mercado que los hacían interesantes.

La baja tecnificación del laboreo de los cultivos determinó la utilización de gran cantidad de mano de obra (peones golondrinas, cosecheros de la zona), que provocó un cierto aumento de la población en la zona (más de 2000 habitantes aproximadamente) y permitió el desarrollo de infraestructuras asociadas, como estufas o desmotadoras por medio de sistemas cooperativos.

En la década del 70 se profundiza la crisis en el sector productivo primario, específicamente en los pequeños productores, lo que obliga al abandono de sus predios y la reconversión hacia el sector ganadero y sus derivados. Esto determina una acelerada implantación de forrajeras (sorgo granífero) complementadas con maíz, dando lugar al crecimiento descontrolado de la población de ciertas especies de animales, que se convierten en nuevas plagas para los cultivos.

A pesar de la crisis planteada se mantienen la superficie cultivada con algodón y tabaco en los grandes predios, a los que se suman las parcelas dedicadas a forrajeras. Paralelo a esto, también se llevan adelante actividades de forestación con especies como eucaliptos y pinos, a partir de políticas incentivadas por el gobierno provincial y nacional que quedarían sin efecto en la década del 80. Por esta época, comienza a desarrollarse sobre la planicie fluvial, en proximidades del pueblo, un sistema de producción hortícola sin mucha tecnificación. Esta situación, junto con el reparto familiar por herencia de lotes, determina un alto parcelamiento de suelos productivos con la consecuente sobre explotación y el agotamiento de dicho recurso.

También existe un aumento de la deforestación debido en un principio a la extracción de especies de importancia económica como se vio en los años 60 y, luego con el tiempo se fueron transformando las superficies boscosas en grandes extensiones herbáceas y sabanas arbóreas con fines ganaderos, cuyas pasturas, en gran parte, estuvieron sobreexplotadas con una fuerte degradación del suelo y su cobertura vegetal. 
A mediados de la década del 80 se realiza el acceso pavimentado a Colonia Benitez que junto con la construcción de la escuela secundaria (ENS No 79 "San Francisco Solano"), significó un cambio trascendental en el desarrollo de la comunidad. En este período se comienza la construcción de barrios de viviendas dentro de los pueblos, situación que con el correr del tiempo se acentúo con nuevos planes del Fonavi, Banco Hipotecario y sistemas de autoayuda, sustentados por subsidios brindados por el gobierno de la provincia del Chaco. Gran parte de estos barrios fueron construidos sobre terrenos bajos, ubicados al noreste del pueblo.

La instalación por parte de dos empresas de hornos, para la fabricación de ladrillos y derivados, sumados a la presencia de diferentes "ladrillarías" (hornos artesanales de ladrillos) fomentados por la fuerté demanda de la edificación incipiente (barrios de viviendas o construcciones particulares) dentro de la colonia como también en el Gran Resistencia, determinó una sobreexplotación del bosque y la sabana arbórea para la obtención de leña utilizada como combustible de estos. También existió una reconversión marcada en lo que se refiere a la producción agrícola, donde el cultivo del algodón y del tabaco son reemplazados por la horticultura, en las proximidades de espejos de agua dulce a partir de pequeñas empresas familiares con una explotación de tipo intensiva y cierta tecnificación (bajo cubierta y riego por esparción).

A fines de la década del 90 la construcción de la Defensa Norte en la zona en el Paraje El Tropezón, dentro del área de estudio, dió lugar por un lado a un fuerte parcelamiento de tierras para su venta, y por otro, a una revalorización de las mismas sujetas a la cotización de la oferta y la demanda. La incipiente construcción de viviendas no sólo como residencias permanentes, sino también con fines de recreación y esparcimiento, ha sido acompañada por una fuerte transformación del paisaje debido a la generación de praderas artificiales y bosques monoespecíficos de especies exóticas; lo que evidencia una revalorización de las tierras no por su valor o aptitud productiva, sino por su valor fiscal o urbano.

Cabe agregar que hasta 1985 la ocupación y parcelamiento de tierra con fines urbanos se realizó sobre la ruta 11 y la antigua entrada a Colonia Benitez. A partir de 1985 hasta 1998 aproximadamente, la tasación inmobiliaria se mantiene por su proximidad al Gran Resistencia, pero los mayores loteos y procesos de compra y venta se traslada hacia la nueva entrada a Colonia Benitez, también conocida como Acceso Pavimentado, ubicada a más de $7 \mathrm{~km}$. de la antigua entrada. Nuevamente la zona vuelve a tener auge a partir 1998, cuando se inician las obras del Plan de Defensa con la apertura de caminos, donde se profundizan los fraccionamientos de tierras, muchos de ellos evadiendo el fisco.

\section{Fase III. PREDIAGNOSTICO}

Como se ha mencionado en apartados anteriores, en la identificación de las problemáticas se parte de un enfoque integrado y sistémico del paisaje, con lo pretensión de brindar lineamientos para el ordenamiento ambiental que el sistema territorial debe alcanzar.

Para dicho planteo se trabajó sobre dos grandes sistemas, el natural y el antrópico; en el primero se tuvo en cuenta solamente aspectos físicos y biológicos que caracterizan el comportamiento del área de estudio, sin por ello pasar por alto la acción humana sobre los mismos. En cambio, el sistema antrópico se organizó a partir de cuatros aspectos dinámicos e interrelacionados entre sí: el productivo (explotación forestal, ganadera, 
agrícola, hortícola e industrial), el inmobiliario, la población y las infraestructuras y servicios.

En relación al sistema natural, tanto el aspecto físico como el biológico presentan una fuerte degradación del medio ambiente, resultado de la acentuación de procesos naturales (erosión, colmatación, inundación) y la alteración de las formaciones vegetales originales a través de la acción antrópica (dilapidación, sobreexplotación, avance de invasoras, extinción).

Con respecto al sistema antrópico, en el aspecto productivo, que implica las actividades primarias y de transformación, la mayor parte de los problemas identificados están relacionados con la degradación del medio por sobreexplotación, erosión, compactación, contaminación y enfermedades, sumados a la escasa rentabilidad económica productiva del mismo por falta de coordinación y complementación de la explotación a nivel predio, a lo que se añade la escasa transformación, preservación, promoción y comercialización de los productos obtenidos.

En el aspecto inmobiliario se hace referencia a los fines de ocupación del suelo. En el mismo, se observa una alteración de las cualidades espaciales por una ocupación anárquica, resultado de una acentuada especulación inmobiliaria, que responde, en primer lugar, a un acelerado crecimiento demográfico y a una densificación urbana por procesos migratorios de ámbitos rurales cercanos y de la ciudad de Resistencia, y en segundo lugar, por su proximidad en distancia y tiempo a esta última, la cual, en las décadas del 80 y 90 ha tenido un rápido crecimiento de la población y del espacio urbanizado.

Esta problemática deriva en un loteo de tierras productivas, artificialización del paisaje con praderas y bosques monoespecíficos de especies endógenas y exógenas indistintamente, deficiencia de servicios e infraestructuras existentes, situación que se profundiza por la ausencia de un proyecto de planificación de expansión urbana y por la carencia de políticas fiscales acordes al uso del suelo.

En el aspecto demográfico se visualiza un crecimiento acelerado de la población, la que se concentra en núcleos ubicados en los parajes Tres Horqueta, y El Tropezón y en el pueblo de Colonia Benitez. Gran parte de esta proviene de ámbitos rurales aledaños, donde las actividades agrícolas se encuentran en una situación de crisis y recesión; aunque en los últimos años, como se comentó más arriba, se observa una marcada tendencia de población proveniente del AMGR en busca de esparcimiento o con fines residenciales, proceso acompañado por un movimiento pendular por cuestiones laborales.

En el caso de la población local, se observa un número importante de personas desocupadas con demandas insatisfechas de viviendas y servicio básicos, lo cual genera asentamientos marginales, bajo condiciones de ilegalidad, en áreas con riesgo de inundación, lo que pone en peligro la integridad física de los mismos, situación que profundiza la presencia de bolsones de pobreza, incrementando hechos delictivos y de inseguridad, tanto en los bienes como en las personas en general.

En relación a la segunda, el posible incremento de los espacios urbanizados a través de viviendas $y$, el creciente interés en adquisición inmobiliaria con un fuerte loteo y artificialización de tierras productivas sin un plan rector que las oriente, advierten para un futuro próximo el carácter urbano de la zona con una densidad de saturación de suelo muy importante, donde la capacidad de contención de los servicios e infraestructuras se 
verán superadas, tornándose deficientes. Esta situación, junto a la falta de coordinación de los actores locales, profundizaría la especulación inmobiliaria alterando las cualidades espaciales y la forma de vida de sus pobladores, a lo que se sumaría un incremento de la confrontación entre vecinos por diferencias de intereses y de costumbres.

En el aspecto de infraestructuras y servicios, las problemáticas observadas son el resultado del marcado crecimiento de la población y el acelerado aumento de las superficies urbanizadas y construidas, complementadas con procesos de ocupación de espacios rurales con fines productivos. Se observa que en ámbitos rurales éstas no respetan la tendencia natural en la mayoría de los casos, por ejemplo el trazado de caminos y alcantarillados deficientes que limitan el escurrimiento del exceso hídrico. En cambio, en ámbitos urbanos se nota la demanda insatisfecha de viviendas de planes sociales, la deficiencia en el abastecimiento de agua potable, la limitada capacidad de contención del sistema educativo y sanitario, y finalmente la carencia de servicios básicos de cloacas, situación que demuestra una notoria pérdida en la calidad de vida de los pobladores.

Además se percibe un descuido de los patrimonios culturales y naturales, por aislamiento e indiferencia a los intereses de la comunidad por parte de los principales actores sociales, o bien, de población inserta proveniente de otros zonas que no se sienten representados por las mismas pautas o ideales.

Definitivamente la falta de cohesión y coordinación, a nivel local, para el mantenimiento y ampliación de infraestructuras y servicios impactan de manera negativa en los sistemas estructurales del equipamiento comunitario, acentuando la crisis en la calidad vida de la población.

Finalmente, teniendo en cuenta lo tratado hasta aquí, se pueden proponer a través de árboles de objetivos posibles oportunidades para superar los problemas, es decir a partir de las situaciones conflictivas o de desequilibrio detectadas se formulan una serie de condiciones o situaciones esperadas en el futuro, que son deseadas y realizables en la práctica.

Fig. 4: PRIORIZACIÓN DE PROBLEMAS

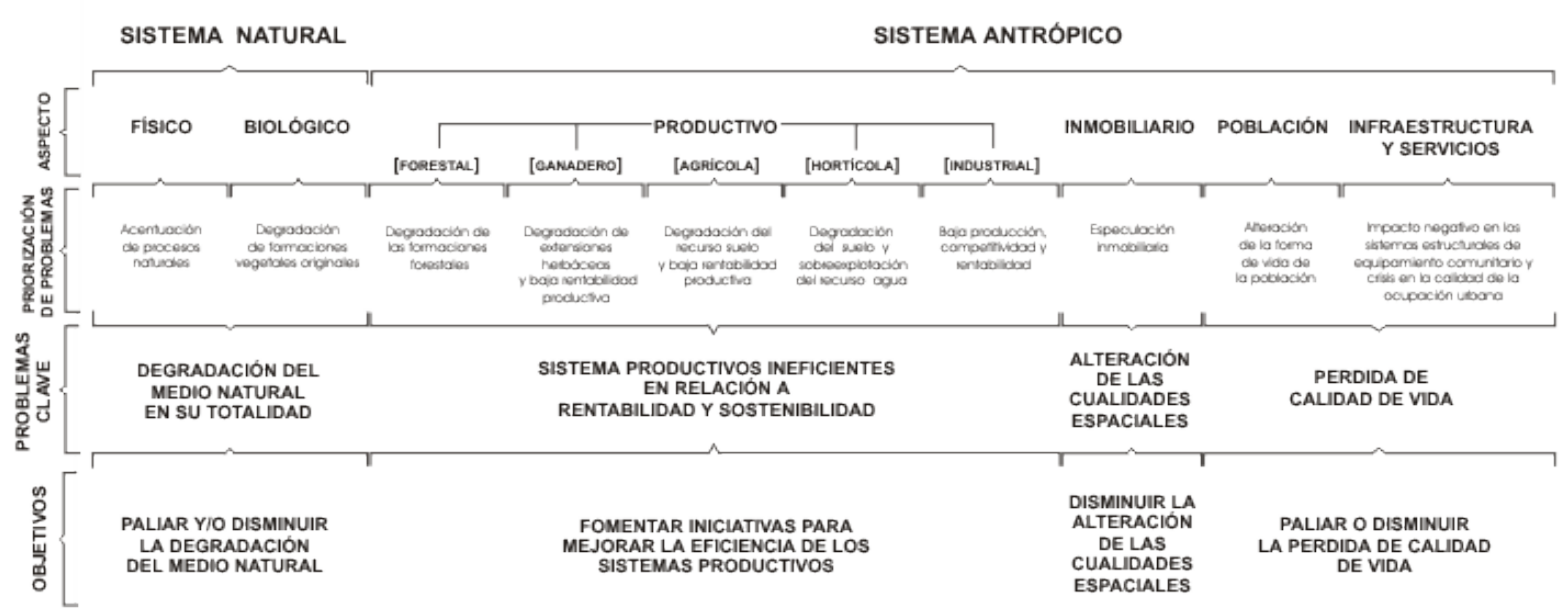

En síntesis, todos los problemas identificados se resumen en cuatro problemas claves, que se detallan a continuación: 
1. Degradación del medio natural original en su totalidad.

2. Sistema productivos ineficientes en relación a rentabilidad y sostenibilidad.

3. Alteración de las cualidades espaciales.

4. Pérdida de la calidad de vida.

A partir de los problemas claves, se han definido los siguientes objetivos tendiente a su solución:

1. Paliar y/o disminuir la degradación del medio natural.

2. Fomentar iniciativas para mejorar la eficiencia de los sistemas productivos.

3. Disminuir la alteración de las cualidades espaciales.

4. Paliar o disminuir la pérdida de la calidad de vida.

\section{Fase IV. DIAGNOSTICO}

\section{a. Análisis de problemas}

Para analizar los problemas detectados se procedió a la realización de cuatro árboles que reflejan las problemáticas más importantes de la zona. Cada uno compuesto de un problema central (el tronco), con sus causas (problemas iniciales o raíces) y efectos (problemas derivados o ramas). Los mismos se detallan a continuación:

El problema central del Árbol de problema $n^{\circ} 1$ es la degradación total del medio natural original en su conjunto que responde a la sobreexplotación y mal manejo que se han hecho del mismo, situación que dio lugar en la actualidad a la baja rentabilidad de la explotaciones.

El Árbol de problema $\mathbf{n}^{\circ} \mathbf{2}$ hace referencia a los sistemas productivos ineficientes en cuanto a rentabilidad y sostenibilidad. El mismo responde a problemáticas ya detalladas en el árbol de problemas $n^{0} 1$, vinculadas al mal manejo 0 sobreexplotación de los recursos naturales, por planteos poco propicios de los sistemas productivos y de comercialización.

El tercer problema analizado en el Arbol de problema $\mathbf{n}^{\circ} \mathbf{3}$, es la alteración de las cualidades espaciales, debido a la acentuación de los procesos migratorios provenientes de ámbitos rurales próximos y del AMGR consecuencia de las problemáticas ya detalladas en el árbol $n^{\circ} 1$ y 2 . Esto genera un proceso de densificación urbana que deriva en una marcada pérdida en la calidad de vida de sus habitantes.

El cuarto problema aparece en Arbol de problema $n^{\circ} \mathbf{4}$, consiste en la pérdida de la calidad de vida de los pobladores de la zona, provocada por las alteraciones de las cualidades espaciales (tanto desde el punto de vista natural como socioeconómico); lo que deriva en la acentuación de este problema central.

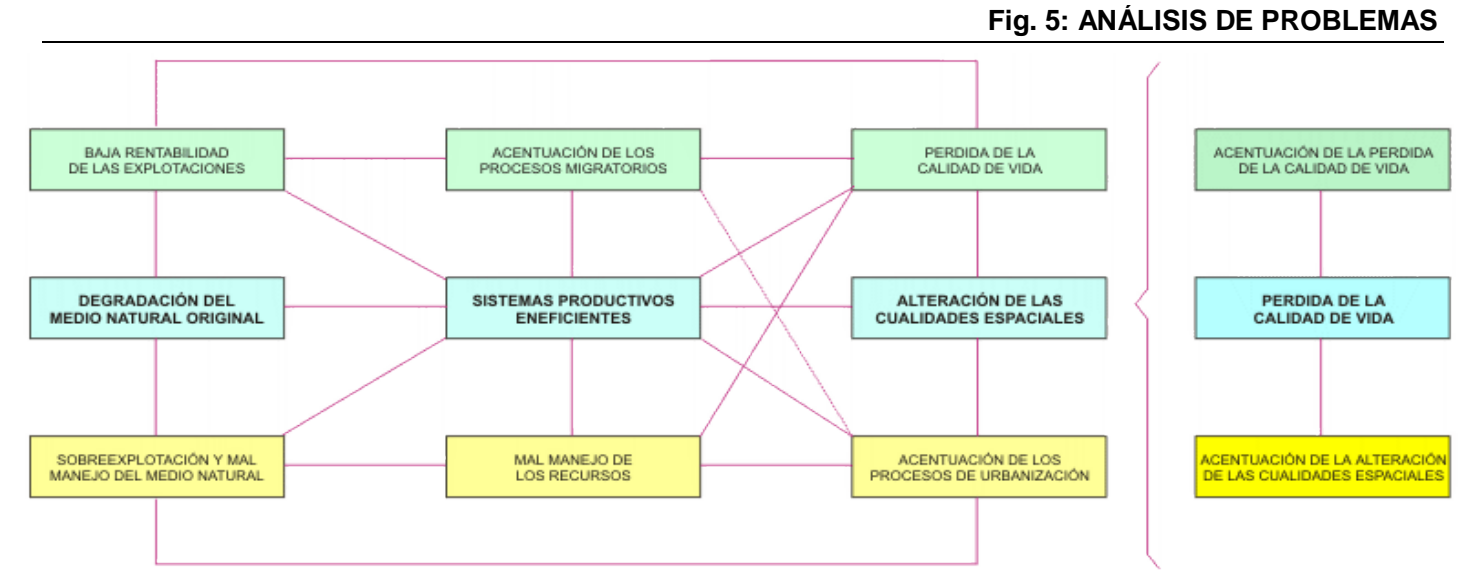




\section{b. Análisis de objetivos}

Para superar los problemas detallados en el apartado anterior se procedió a la realización de cuatro arboles de objetivos en los que se pretende brindar condiciones positivas, deseables y realizables. Cada uno está compuesto por el tronco u objetivo central para superar el problema correspondiente, que se sustenta en las raíces, conformadas por el objetivo inicial que sugiere los mecanismos para alcanzarlo o pautas a tener en cuenta para su consecución y, las ramas u objetivo derivado que corresponde a los efectos o consecuencias que se obtendrían de aplicarse el objetivo central. Así por lo ante expuesto tenemos que:

- El objetivo principal del Arbol de objetivo $n^{0} 1$ sería paliar o disminuir la degradación del medio natural original, a partir de la generación de proyectos productivos sustentables y poco agresivos a éste, lo que derivaría en una mejor calidad de vida de la población en general.

- El Arbol de objetivo $\mathbf{n}^{\circ} \mathbf{2}$ surge como respuesta al problema de los sistemas productivos ineficientes (en relación a rentabilidad y potencialidad). En el mismo se pretende fomentar iniciativas para mejorar la eficiencias de los sistemas productivos a partir de proyectos alternativos, o potenciando los existentes de manera sustentable, hecho que permitiría preservar el entorno rural y natural, mejorando de esta manera la calidad de vida de la población.

- En el objetivo central del Arbol de objetivo $\mathbf{n}^{\mathbf{3}} \mathbf{3}$, se pretende disminuir la alteración de las cualidades espaciales a partir de limitar la ocupación anarquíca del espacio, cuyo efecto, permitiría mejorar y mantener la calidad de vida de los pobladores; hecho que se pretende como resultado en los arboles de objetivo desarrollados.

- El objetivo principal del Arbol de objetivo $\mathbf{n}^{\circ} \mathbf{4}$, es la síntesis obtenida del replanteo de los otros objetivos antes analizados. En el mismo se insiste en la necesidad de disminuir la pérdida de la calidad de vida a partir, de la posibilidad de paliar la alteración de las formas de vida que tiene la población en los últimos tiempos, por las razones ya detalladas como la crisis de los sistemas productivos e institucionales, la ocupación anárquica, la desocupación, la especulación, la degradación del medio ambiente natural y social, entre otras.

De cumplirse, se podría mejorar y mantener la calidad de vida de los pobladores; es decir, la concreción de viviendas y servicios adecuados, posibilidades laborales, presencia de espacios verdes, mantenimiento de ciertas pautas culturales, revalorización del habitante rural, etc.

FIG. 6: ANÁLISIS DE OBJETIVOS
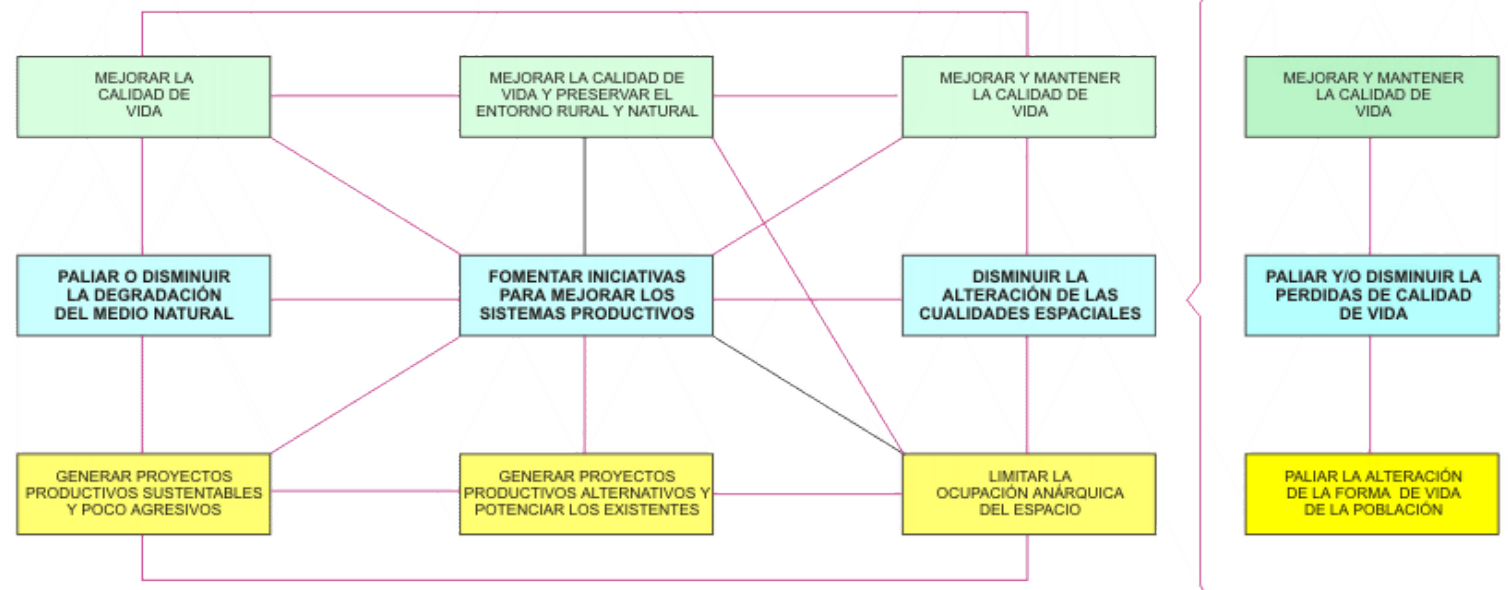


\section{Fase V. GESTIÓN}

De acuerdo con el análisis de los principales problemas detectados y objetivos definidos para lograr un adecuado desarrollo en la zona, sumados al cruzamiento de información sobre las oportunidades, se han formulado las siguientes propuestas para el impulsar un escenario de gestión deseable o factible de realizar:

Propuesta 1: La zona presenta la necesidad de preservar espacios relictuales de formaciones vegetales a partir de un corredor de biodiversidad.

Propuesta 2: Surge la necesidad de realizar estudios que profundicen la información existente sobre el comportamiento y tendencia del medio natural y la acción antrópica, a través de la participación de instituciones públicas como el INTA y la UNNE, rescatando el conocimiento empírico del lugareño y fomentando la participación de la población en la gestión de recursos .

Propuesta 3: Explotar las potencialidades turísticas del área, sacando provecho del patrimonio cultural y natural.

Propuesta 4: Replantear y potenciar el sector agrario de la zona, a través de la coordinación de esfuerzos en el desarrollo integrado y competitivo de las explotaciones.

Propuesta 5: El área en cuestión puede promover inversiones para su desarrollo económico, a través de subsidios o créditos blandos apoyados en los planteos de las propuestas 3 y 4.

Propuesta 6: Generar oportunidades laborales por medio del desarrollo y la implementación de políticas de participación social.

Propuesta 7: Controlar y ordenar el usos del suelo con fines urbanos por medio de un plan rector de ocupación.

Propuesta 8: Elaborar y desarrollar políticas de asentamiento y movimientos migratorios, a través de la participación de la comunidad, por medio del diseño e implantación de proyectos de gestión concertada que se elaboren a partir de los planteos de las propuestas 5, 6 y 7.

\section{Escenario Tendencial}

Pese a que no todos los comportamientos de las variables estudiadas son perfectamente conocidos, se observa una manifiesta tendencia negativa en general, plasmada en una serie de procesos que se suceden en el área, y de no tomarse las medidas preventivas pertinentes se acentuarían, dando lugar a problemáticas aún más complejas que las diagnosticadas y analizadas en este trabajo, por lo tanto más difíciles de paliar y solucionar. Las mismas se detallan a continuación:

1. Procesos de erosión y colmatación.

2. Procesos de degradación de la cobertura vegetal original.

3. Profundización de la crisis en los sistemas productivos.

4. Alteración de las cualidades espaciales.

5. Densificación urbana con deficiencia de servicios básicos.

6. Concentración de población en áreas de riesgo.

Esto derivaría en una profundización en la pérdida de la calidad de vida, de los pobladores del lugar, por una acentuación de las alteraciones, tanto naturales como socioeconómicas, detalladas con anterioridad. 
Fig. 7: ESCENARIO TENDENCIAL
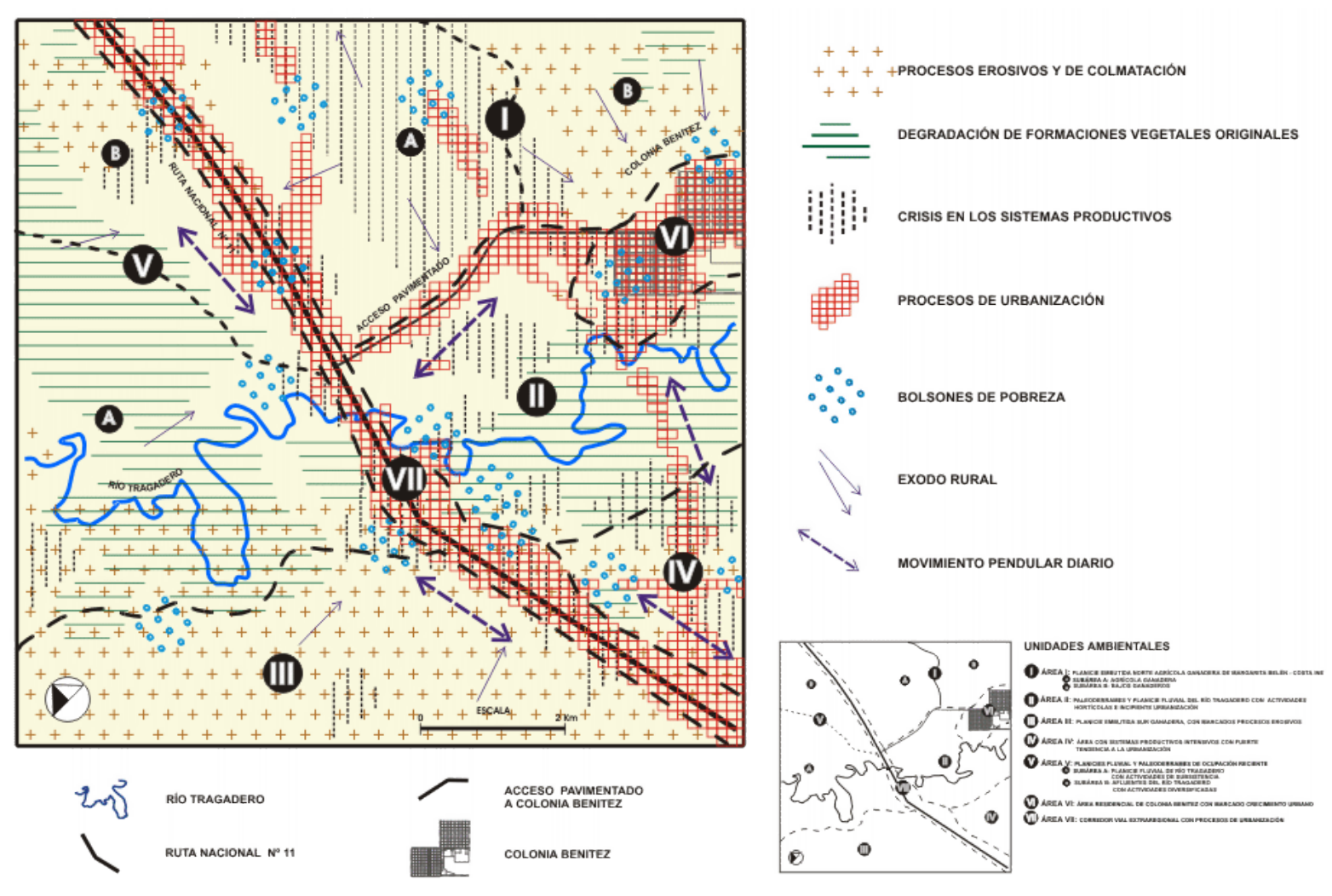

\section{Escenario Deseado}

Para contrarrestar la tendencia negativa, de los procesos detallados a lo largo del trabajo, se representa el futuro que se pretende alcanzar a partir de criterios preestablecidos, en relación a propuestas de desarrollo, que tienen en cuenta las limitaciones y potencialidades que ofrece el territorio desde el punto de vista natural y antrópico ( fig. 2 ). Para ello se rescata las siguientes propuestas ya analizadas en párrafos anteriores:

1. El ordenamiento de la tierra como unidad de producción en relación de su capacidad productiva.

2. La preservación de espacios relictuales de formaciones vegetales originales.

3. La preservación del patrimonio histórico arquitectónico de la zona.

4. La confección de proyectos productivos alternativos, novedosos y sustentables.

5. La potenciación de los sistemas productivos existentes.

6. La planificación de la tierra, con fines residenciales o de inversión, acorde al contexto rural.

7. La generación de oportunidades laborales para la población local.

8. La disminución de la alteración de las cualidades espaciales que permita mejorar y mantener la calidad de vida, de sus pobladores, en la totalidad del área de estudio. 
Fig. 8: ESCENARIO DESEADO
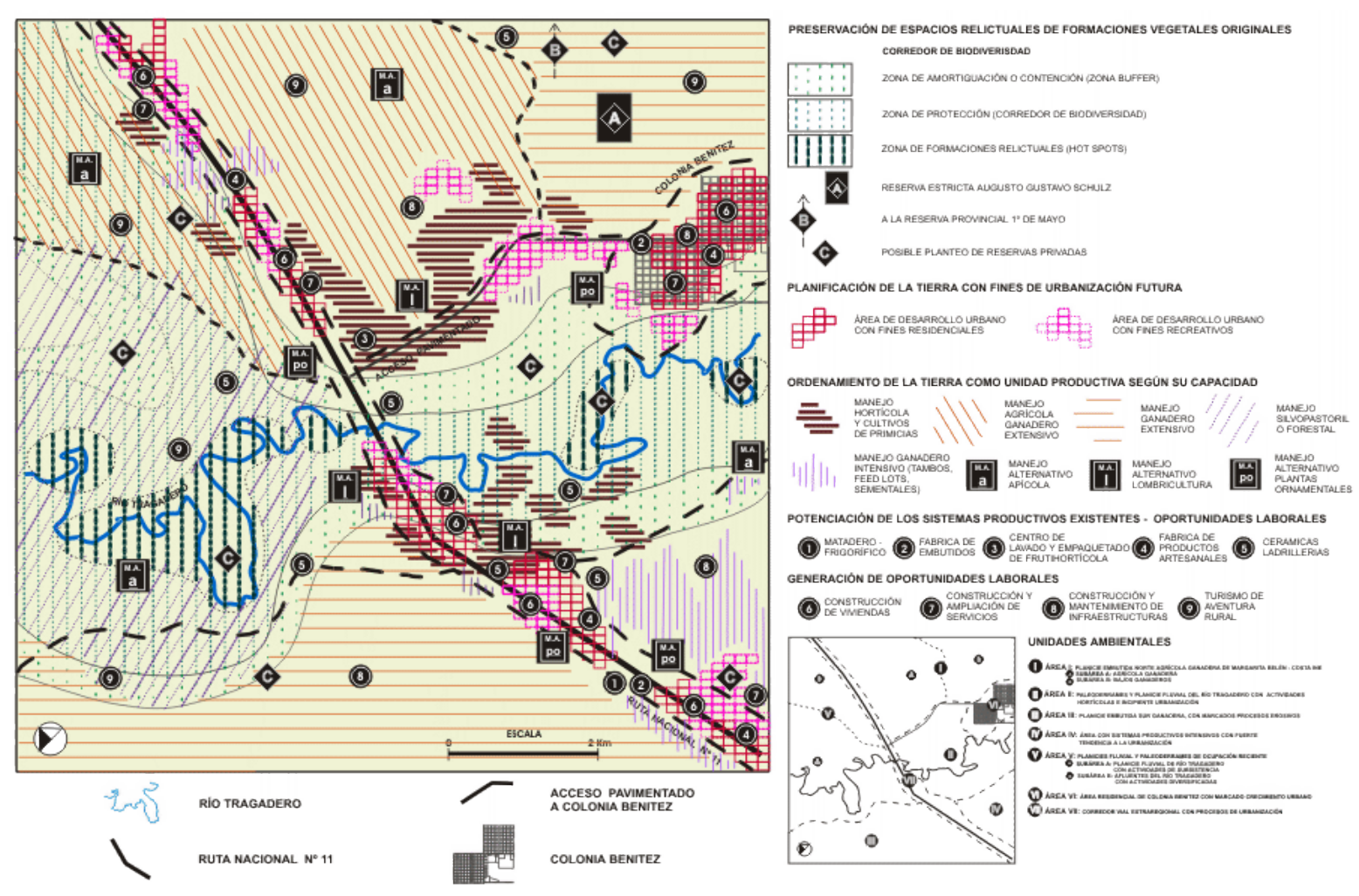

\section{CONCLUSIÓN}

El presente trabajo, se realizó con fines meramente académicos, su desarrolló se basó en una metodología para el estudio integrado del paisaje, apoyada en una concepción geográfica y sistémica del paisaje que permitió analizar el proceso de ocupación en un área rural específica y proyectar escenarios futuros.

El método propuesto, aplicado en un área periurbana del AMGR, presenta como limitante el no haber sido puesto en práctica por un equipo interdisciplinar, condición que hubiera enriquecido aún más su potencialidad. El método aquí presentado es lo suficientemente flexible para ser aplicado a espacios con características muy diferentes y con fines muy diversos, que pueden ir desde el diagnóstico hasta la gestión propiamente dicha.

Además presenta la posibilidad de trabajar de manera independiente cada una de sus fases, de acuerdo con la existencia y disponibilidad de información, equipamiento, tiempo disponible, cantidad de personal idóneo y recursos económicos que se dispongan . Pudiéndose obtener en su aplicación, solamente, una caracterización (Fase I y II) en el caso que signifique recopilar, organizar y actualizar la información existente o, bien generar información de base en aquellas áreas que no existan estudios previos, situación que daría una visión amplia de la situación ambiental, permitiéndo dar lineamientos generales a seguir. Al llegar a la Fase III se puede lograr un prediagnóstico, si existe material disponible que permita una descripción, delimitación y estructuración del territorio en áreas, distinguiéndose pautas repetibles, complementarias y asociadas de manera peculiar. Paso seguido se llega a un diagnostico (Fase IV), concretada a partir del análisis de los resultados anteriores, donde solamente se haga hincapié en los problemas 
detectados, destacando las causas que los generan y las consecuencias derivadas y, además el planteo de los objetivos para superarlos, es decir las líneas de acción y los efectos esperados. Finalmente, se establecen las pautas de gestión (Fase V) que permiten llevar adelante el ordenamiento del territorio por medio de propuestas de escenarios futuros, que deberán tener en cuenta las potencialidades y limitaciones del área en cuestión. Cabe recordar que siempre existe la posibilidad de aparición de una variable de peso que modifique o altere la tendencia actual y que dé lugar a un escenario muy diferente al proyectado.

Con relación al área periurbana donde se aplicó el modelo propuesto, esta presenta una estructura de espacio agropecuario con incipientes procesos de urbanización, vinculados a una red urbana organizada por el AMGR. En la misma se detectó la necesidad de:

- El ordenamiento de la tierra como unidad productiva, sea para venta o arrendamiento, como un concepto de bien de cambio en producción, con una posibilidad cierta de ordenamiento de la capacidad productiva.

- La planificación de la tierra con fines residenciales o de inversión, que limite la especulación inmobiliaria y permita un crecimiento urbano acorde al contexto rural.

- La disminución de la alteración de las cualidades espaciales, a partir de establecer límites a la ocupación anarquíca del espacio, cuyo efecto, permitiría mejorar y mantener la calidad de vida de los pobladores.

Para ello se proponen áreas determinadas por estructuras vinculantes con el sistema productivo rural y el proceso de urbanización incipiente. Teniendo en cuenta los aspectos antedichos, que inciden sobre el área de estudio, surge la necesidad de profundizar e insistir en las líneas de acción futuras como:

- Estudiar las tecnologías posibles de aplicar sin pérdida de puestos de trabajo por expulsión.

- Desarrollar sistemas productivos novedosos, alternativos, complementarios y diversificados que exploten los recursos locales de manera sustentable.

- Definir y potenciar centros críticos de desarrollo económico local, poniendo el esfuerzo en identificar núcleos urbanos que presenten un potencial desarrollo en apoyo de las actividades agropecuarias, para ello se deberá tener en cuenta:

- El papel de los actores sociales y las instituciones implicadas.

- El replanteo de políticas que obstaculizan su desarrollo y la potenciación de aquellas que lo faborecen.

- Definir cuáles son los estrangulamientos que impiden un funcionamiento más eficaz.

- Trabajar en el incremento del intercambio comercial entre centros poblados cercanos para que se conviertan, además, en centros de distribución de los productos agrarios, fuentes para abastecer de conocimientos técnicos y recursos para la elaboración de productos destinados al consumo provincial.

- Paliar el acceso insuficiente o la mala distribución de tierras, ya sea por obstáculos políticos, sociales, inmobiliarios y económicos, una de las barreras más graves para el desarrollo sustentable, tanto éstas tengan fines productivos como fines residenciales.

- Legislar para limitar la usurpación de tierras por medio de un sistema no sujeto a la escrituración usual de la propiedad privada, para ello se deberá determinar la propiedad de las parcelas y registrar el derecho de los individuos sobre los terrenos, a partir de normas que resulten accesibles a los grupos desfavorecidos y de bajos ingresos. 
- Proponer medidas enérgicas para limitar la expansión urbana en las zonas agrícolas fértiles, conservándolas para la producción de alimentos y como espacios libres de contaminación.

- Construir la estructura que orienten el cambio de la actividad urbana y de la actividad rural, trabajando a favor de educar en una cultura acorde con el desarrollo sustentable.

\section{BIBLIOGRAFÍA}

1. AlBeRTO, Jorge A. (2004). "Caracterización de los usos del suelo de un espacio periurbano del Gran Resistencia". Revista Geográfica Digital. Instituto de Geografía. Facultad de Humanidades. UNNE. ISSN 1668-5180. Resistencia.

http://hum.unne.edu.ar/academica/institutos/geografia/Geo1/homeig0.htm.

2. ALBERTO, Juan A. (1990). "El proceso de ocupación del espacio argentino". Instituto de Geografía. Facultad de Humanidades . U.N.N.E. Resistencia. Chaco. Argentina.

3. CODAZZI (2000) "Guía del Plan de Ordenamiento Territorial" http://www.igac.gov.co/ordenet/iga00004.htm

4. ECHECHURI, Hector (1998). "Evaluación ambiental y sistemas de ciudades". Documento del curso: "La Gestión Ambiental en el Desarrollo Urbano". Maestría de Gestión Ambiental del Desarrollo Urbano GADU. Facultad de Ingeniería. Universidad Nacional del Comahue. Neuquén.

5. FAINBERG, Aaron(1998). "Aspectos de la Gestión Ambiental en un Ambiente Antropizado". Documento del curso: "La Gestión Ambiental en el Desarrollo Urbano". Maestría de Gestión Ambiental del Desarrollo Urbano GADU. Facultad de Ingeniería. Universidad Nacional del Comahue. Neuquén.

6. FERNÁNDEZ, Roberto (1998). "Componentes teóricos y metodológicos de la Gestión Ambiental". Documento del modulo 1. Maestría de Gestión Ambiental. Facultad de Arquitectura y Urbanismo. UNNE. Resistencia. Chaco.

7. GEORGES OLIVER (1981). "La ecología humana". Colección ¿qué sé? Nueva Serie 136. OIKOS - TAU. Barcelona (España).

8. GOMEZ OREA, D. (1985). "El espacio rural en la ordenación del territorio". Instituto de Estudios Agriarios, Pesqueros y Alimentarios. Madrid.

9. GOMEZ OREA, D. (1992). "Planificación rural". Ed. Agrícola Española. Madrid.

10. IBARRA BENLLOCH, P. (1993). "Una propuesta metodológica para el estudio del paisaje integrado". En Geographicalia 30. Revista del Departamento de Geografía y Ordenación del Territorio. Universidad de Zaragoza. 229-242. Diciembre 1993

11. Ministerio de Obras Publicas, Transporte y Medio Ambiente. (1995) "Guía metodológicas para la elaboración de estudios de impacto ambiental.", Series monográficas. Ministerio De Obras Publicas, Transporte y Medio Ambiente. Secretaría de Estado de Medio Ambiente y Vivienda. Madrid, (España).

12. POPOLIZIO, E. (1989) "Algunos elementos geomorfológicos condicionantes de la organización espacial y las actividades del NEA", Geociencias $n^{\circ}$ XVII, Centro de Geociencias Aplicadas, U.N.N.E., Resistencia.

13. REBORATTI, Carlos (1999). "Estructura y dinámica del territorio". Documento del modulo 4. Maestría de Gestión Ambiental. Facultad de Arquitectura y Urbanismo. UNNE. Resistencia. Chaco.

14. ROCCATAGLIATA, Juan (1998). "Ordenamiento Territorial y Sistemas de Ciudades". Documento del curso: "La Gestión Ambiental en el Desarrollo Urbano". Maestría de Gestión Ambiental del Desarrollo Urbano GADU. Facultad de Ingeniería. Universidad Nacional del Comahue. Neuquén. 
15. ROMA PUJADAS y JAUME FONT (1998). "Ordenación y Planificación Territorial" Espacios y Sociedades. Serie Mayor. Editorial Síntesis. (Madrid) España.

16. SCORNIK, Carlos (1998.). "Diagnóstico Expeditivo AMGR". Ministerio del InteriorPrograma de Protección Contra Inundaciones (PPI). SUPCE Convenio BIRFProvincia del Chaco. 